\title{
EXPECTATIVAS E CONCEPÇÕES DE TRABALHO NA VELHICE EM HOMENS NA MEIA-IDADE
}

Milena Cristina de Freitas

Universidade São Judas Tadeu

Tatiane Dornelas Campos

Universidade São Judas Tadeu

Claudia Aranha Gil

Universidade São Judas Tadeu

\begin{abstract}
Resumo
Objetivou-se neste artigo analisar as expectativas e concepções de trabalho na velhice em homens de meia-idade. Trata-se de uma pesquisa qualitativa que contou com a participação de quinze homens na faixa etária entre 50 e 59 anos que trabalham em atividade formal ou informal. Realizou-se uma entrevista semiestruturada e aplicação da técnica projetiva denominada procedimento Desenhos-Estórias com Tema. Para a análise dos dados utilizou-se a técnica de Análise de Conteúdo. Foram identificadas categorias como expectativas e representações diante da velhice, trabalho e aposentadoria. Observou-se que as expectativas diante da aposentadoria foram associadas ao desejo em praticar atividades prazerosas, porém os dados da realidade sobre a instabilidade financeira e responsabilidades com os familiares não permitem que os participantes na meia-idade parem suas atividades profissionais. $O$ estudo demonstra que as expectativas e concepções de trabalho na velhice estão, de modo geral, associadas tanto a continuidade quanto a sua ressignificação nessa fase da vida. Palavras-chave: Envelhecimento; Trabalho; Maturidade; Homens.
\end{abstract}

\section{EXPECTATIONS AND WORKING CONCEPTS IN OLD AGE IN MIDDLE-AGED} MEN

\begin{abstract}
This study aimed to analyze the expectations and conceptions of work in old age in middle-aged men. This is a qualitative research that included the participation of fifteen men between 50 and 59 years working in formal or informal activity. A semistructured interview and the projective technique called Story-Drawing procedure with theme was held. For data analysis was used the content analysis technique. Categories were identified as expectations and representations before old age, work and retirement. It was observed that retirement expectations were associated with the desire to practice pleasurable activities, but financial instability and responsibilities with family members do not allow participants in middle-aged to stop their professional activities. This study shows that the expectations and conceptions of work in old age are generally associated with both continuity and its reinterpretation in this phase of life.
\end{abstract}

Keywords: Aging; Job; Maturity; Men. 


\title{
EXPECTATIVAS Y CONCEPTOS DE TRABAJO EN LA VEJEZ EN LOS HOMBRES EN MEDIANA EDAD
}

\begin{abstract}
Resumen
Este estudio tuvo como objetivo analizar las expectativas y concepciones de trabajo en la vejez en los hombres de mediana edad. Se trata de una investigación cualitativa que contó con la participación de quince hombres entre 50 y 59 años de trabajo en la actividad formal o informal. Se realizó una entrevista semiestructurada y la técnica proyectiva llamado procedimiento de Historia-Dibujo con el tema. Para el análisis de datos se utilizó la técnica de análisis de contenido. Categorías fueron identificadas como las expectativas y representaciones ante la vejez, el trabajo y la jubilación. Se observó que en las expectativas de jubilación se asociaron con el deseo de practicar actividades placenteras, pero los datos de la realidad sobre la inestabilidad y las responsabilidades financieras con miembros de la familia no permiten a los participantes en la mediana edad detener sus actividades profesionales. El estudio muestra que las expectativas y concepciones de trabajo en la vejez están generalmente asociados con la continuidad y su reinterpretación en esta fase de la vida.
\end{abstract}

Palabras clave: Envejecimiento; trabajo; madurez; hombres.

\section{INTRODUÇÃO}

Entender a fase da meia-idade faz-se necessário para a compreensão da velhice, pois esta caracteriza uma fase de transição que coloca em evidência expectativas e planos diante do envelhecimento. Existem muitas maneiras de vivenciar a meia-idade, por essa razão, há uma impossibilidade de apresentar uma única definição que possa expressá-la. Dos 50 aos 59 anos de idade é comum que $o$ indivíduo crie expectativas, planos e anseios com esse futuro próximo, construindo representações de como será o trabalho na velhice e o processo de envelhecimento. Em estudo realizado por Antunes e Silva (2014), identificou-se pouca literatura sobre o tema "meia-idade", sendo constatado que muito dos referenciais teóricos ligados ao assunto são embasados em estudos sobre a velhice.

Destaca-se a importância de estudar homens na meia-idade para compreender como são vivenciadas as transformações no contexto social atual e as mudanças intrínsecas à idade. Partindo do contexto de uma sociedade que pressiona e muitas vezes os julgam, alguns homens ainda se sentem mobilizados a não mostrar a fragilidade inerente ao ser humano em diferentes fases da vida e, nesse sentido, buscam manter-se provedores da família, porém vivenciam na realidade uma crise de meia-idade masculina que pode se potencializar na velhice (Silva \& Silva, 2014; Trindade, 2002).

Segundo Neri (2013), é necessário considerar o envelhecimento a partir da definição de um fenômeno biológico, psicológico e social que será determinado, principalmente, pela cultura em que o indivíduo está inserido. Sob essa ótica, o envelhecimento na sua atual concepção caracteriza-se, não apenas como um processo natural determinado pelo tempo cronológico, mas pela desconstrução e construção da identidade da pessoa. Desse modo, o idoso passa por muitas mudanças ao longo da vida e poderá dar um sentido diferente a essas 
transformações. Portanto, toda pessoa envelhece a seu próprio modo, pois cada um escreveu, escreverá ou reatualizará a sua própria história de vida a partir de suas vivências na infância, juventude, idade adulta e na meia-idade (Abras \& Sanches, 2010; Silva \& Finocchio, 2011).

A velhice atualmente é notada como uma fase do desenvolvimento de continuidade da vida e não mais uma época marcada somente pelas perdas, como era postulado até a década de 1970. Sendo assim, observa-se uma importante mudança paradigmática que, a partir dos aportes teóricos de autores como Jung e Erikson, contribuiu para que se chegasse à conceituação atual. Nesse sentido, Erik Erikson (1902-1994) baseou sua teoria no desenvolvimento da personalidade como um processo contínuo ao longo da vida, assim como Jung (1875-1961), que considerou os últimos anos de vida como preciosos para fazer uma revisão da vida e para reparar erros (Erikson, 1998; Jung, 1971; Sá \& Souza, 2015).

Segundo Neri (2006), as teorias precursoras citadas acima, bem como o paradigma dialético, o behaviorismo e a psicologia da aprendizagem americana, entre outras, deram embasamento ao conceito de Life-Span, paradigma de desenvolvimento ao longo de toda a vida, criado por Paul B. Baltes (1939-2006). O desenvolvimento dessa teoria aponta para uma perspectiva de um desenvolvimento contínuo ao longo da vida, onde não ocorre a estagnação. Assim, o envelhecimento bem-sucedido inclui a escolha de metas prováveis de serem alcançadas e a busca de compensações quando isso ocorre, levando o idoso a fazer e ser o melhor possível com os recursos que dispõe (Baltes, 2000).

Segundo Fontes (2010), a perspectiva do Life-Span prevê que, apesar de as perdas tornarem-se presentes no processo de envelhecimento, os idosos podem apresentar considerável estabilidade, autoestima, competência, autoeficácia e qualidade de vida, sendo que essa ideia é fundamental para o conceito de envelhecimento ativo. Desse modo, as ações de saúde, participação e segurança compõem a definição de envelhecimento ativo, sendo que ativo não se refere somente a capacidade física, diz respeito também à participação do idoso na força de trabalho, pois permite que o idoso se sinta útil e reconhecido na sociedade. Além disso, o termo 'ativo' abrange o envolvimento do idoso nas questões sociais, econômicas, culturais, espirituais e civis que o rodeiam (Franco \& Barros Jr., 2013).

A presença de pessoas idosas ativas na sociedade brasileira é uma tendência. Segundo dados do Instituto Brasileiro de Geografia e Estatística (IBGE; 2013), a população com faixa etária acima de 65 anos deve passar para 58,4 milhões (26,7\% do total) em 2060, ou seja, quadruplicará a quantidade de idosos no país. Existe também a perspectiva de que a expectativa de vida será de 81 anos de idade em 2060. Estudos realizados pelo Instituto de Pesquisa Econômica Aplicada (IPEA; 2009), constataram que, como consequência do envelhecimento populacional, há fortes indícios da participação de idosos 
aposentados acima de 60 anos na força de trabalho e isto tem sido cada vez mais frequente. Neste sentido, as pessoas atualmente estão vivendo mais, sendo isso uma grande característica da sociedade, pois são novos tempos que marcam essa e futuras gerações de idosos. Observa-se que as pessoas estão mais preocupadas com a qualidade de vida e procuram manter-se mais ativas em grupos sociais e, principalmente, no trabalho (Fontes, 2010; Neri, 2006; Wajnman, Oliveira \& Oliveira, 2004).

O trabalho, seja considerado ele formal ou informal, é uma construção social que, ao longo da história da humanidade, adquiriu vários significados, desde aspectos ligados ao labor penoso relacionado a um sentido emocional, até as conotações voltadas a realizações e satisfações perante a sociedade (Albornoz, 2000; Peres, 2014). A continuidade das atividades profissionais é característica do idoso que se aposenta e continua sua atividade profissional. Uma das razões dessa continuidade diz respeito à necessidade do idoso manterse produtivo e valorizado e conseguir manter um padrão de vida financeira aceitável. Além disso, pode ser uma estratégia também para vencer a solidão e o isolamento que o cerca (Sá et al., 2011).

Em estudo sobre imaginários de aposentadoria, trabalho e velhice, constatou-se nos participantes o forte imaginário negativo em relação ao envelhecimento. A aposentadoria foi encarada como um benefício possível, desde que não seja vinculada ao encerramento das atividades profissionais (Moreira, 2011; Scortegagna \& Oliveira, 2012). Tendo em vista que pensar na aposentadoria é mais frequente na fase que a antecede, as pessoas na meiaidade criam expectativas e planos. A transição para a aposentadoria pode ser analisada sob duas perspectivas. Uma é a possibilidade de descanso remunerado, que proporcionará mais tempo aos interesses pessoais e familiares, porém, a outra perspectiva é menos otimista e implica redução da capacidade financeira, perda de vínculos afetivos do ambiente de trabalho, perda de status profissional, além de sentimentos de inutilidade e insegurança (Zanelli, 2008).

Considerando a importância do impacto do envelhecimento populacional a nível mundial, bem como do aumento do número de idosos que continuam atuando profissionalmente, torna-se relevante estudar pessoas na meia-idade, pois elas estão em uma fase da vida que antecede a velhice. Partindo da hipótese de que os homens na meia-idade têm como expectativa profissional continuar a trabalhar para manter a estabilidade financeira e também sua inserção social, essa pesquisa teve o objetivo de identificar as expectativas e concepções de trabalho na velhice, bem como discutir a percepção de velhice dos participantes e analisar as expectativas e o significado de trabalho relacionado à aposentadoria. Para isso foi realizado um estudo qualitativo com a utilização de instrumentos como questionário sócio demográfico, entrevista semiestruturada e a utilização de uma técnica projetiva denominada desenho-estória com tema (Aiello-Vaisberg, 1997). 


\section{MÉTODO}

A pesquisa de abordagem qualitativa ocorreu no Estado de São Paulo junto a homens na meia-idade trabalhando em atividades formais e informais. Tal método apresentou-se mais adequada ao alcance dos objetivos propostos, possibilitando a busca da compreensão da dinâmica do ser humano, partindo do significado vivenciado para o indivíduo sobre expectativas e representações de trabalho na velhice (Turato, 2005). Para a análise dos dados utilizou-se a análise de conteúdo de Bardin (2006), através de uma investigação que tem por finalidade a descrição objetiva e sistemática do conteúdo manifesto da comunicação dos participantes. Visa-se, com isso, compreender os elementos que formam a vivência e percepção dos homens na meia-idade sobre o envelhecimento, trabalho e aposentadoria na velhice. Os significados produzidos pelos participantes sobre suas vivências foram interpretados com base na literatura específica sobre o tema. Por meio desse estudo, espera-se contribuir para que pesquisadores e profissionais da saúde e recursos humanos possam atuar de maneira mais eficaz em conjunto com homens na meia-idade próximos ao processo de aposentadoria.

\section{Participantes}

Foram selecionados para o estudo 15 trabalhadores do sexo masculino da cidade de São Paulo que atuam em atividade remunerada formal ou informal, na faixa etária entre 50 e 59 anos. Os participantes foram enumerados de 1 a 15 . Dos quinze entrevistados, sete tinham, na ocasião da entrevista, idades entre 50 e 53 anos, sete entre 56 e 57 anos e apenas um com 59 anos. A maioria declarou ser casado ou manter união estável e possuir filhos.

Quanto à escolarização, sete têm ensino superior completo, três têm ensino médio completo e um tem ensino médio incompleto, com ensino fundamental completo são dois participantes e dois com ensino fundamental incompleto. Oito dos participantes, embora não tenham curso superior completo, declararam que já realizaram cursos extras curriculares, como segurança patrimonial, noções administrativas, informática, construção civil, entre outros. Metade dos participantes permanece na mesma empresa entre 20 a 30/40 anos.

A maioria dos participantes ainda não é aposentada, sendo que cinco são aposentados que continuam trabalhando. Quanto ao tipo de vínculo empregatício, treze atuam formalmente e dois de modo informal.

\section{Instrumentos e procedimentos}

A pesquisa foi aprovada no Comitê de Ética em Pesquisa sob o número 1.031.349. Inicialmente foi feito um contato com os participantes indicados, no qual foram esclarecidos os objetivos da pesquisa e o método proposto e lido o Termo de Consentimento Livre e Esclarecido (TCLE). 
$\mathrm{Na}$ coleta de dados, aplicou-se inicialmente um roteiro de caracterização. Em seguida, realizou-se o Procedimento Desenhos-Estórias com Tema (AielloVaisberg, 1997). Esse instrumento é baseado no Procedimento Desenho-Estória de Walter Trinca (1972). Trata-se de uma técnica projetiva que visa compreender o imaginário coletivo e investigar a representação com relação à temática abordada (Trinca, 2013). Foi pedido que o participante realizasse duas unidades de desenhos com lápis grafite em folha sulfite e, em seguida, contasse estórias sobre o que desenhou. O primeiro desenho teve como instrução: "Desenhe uma pessoa idosa que trabalhe e conte uma estória". Quanto à segunda unidade, a solicitação foi: "Desenhe uma pessoa aposentada e conte uma estória". Posteriormente foi realizada uma entrevista semiestruturada com perguntas elaboradas pelas pesquisadoras para levantamento de informações a respeito dos participantes e sobre a temática abordada.

\section{Análise dos dados}

Com relação à técnica de análise de conteúdo (Bardin, 2006), primeiramente foram definidos os temas mais frequentes, sendo que as entrevistas e as estórias dos desenhos foram lidas na íntegra. Foram destacadas então as unidades de significado de acordo com a ordem crescente que apareceram na fala dos participantes. As categorias temáticas foram definidas por critérios de frequência, sendo que as mais presentes foram: a) expectativas diante da velhice, b) concepção de trabalho e expectativas e c) representações diante da aposentadoria e do trabalho na velhice. A partir desses temas foram encontradas unidades de significado apresentadas nos resultados por ordem de frequência. O material resultante da aplicação do Procedimento de DesenhosEstórias com Tema (Aiello-Vaisberg, 1997), levando em conta a produção do desenho acompanhado da estória contada e o conteúdo das entrevistas, foi analisado em conjunto.

Segundo Bardin (2006), para aumentar o grau de confiabilidade da análise, podem ser utilizados juízes para identificar e comparar as unidades de significado, sendo esse procedimento opcional ao pesquisador, porém sua prática eleva o nível de confiabilidade do estudo. Nesse sentido, considerou-se a classificação proposta pelas pesquisadoras e orientadora que atuaram como juízes internos. Assim, cada uma criou suas unidades de significado e depois estas foram comparadas e discutidas em conjunto. Após esse processo foram selecionadas as principais categorias apresentadas em termos de maior frequência de ocorrência e analisadas com base na literatura sobre o tema. 


\section{RESULTADOS E DISCUSSÃO}

A partir da análise de conteúdo, geraram-se os eixos temáticos apresentados na Figura 1, com suas respectivas categorias e subcategorias, discutidos a seguir.

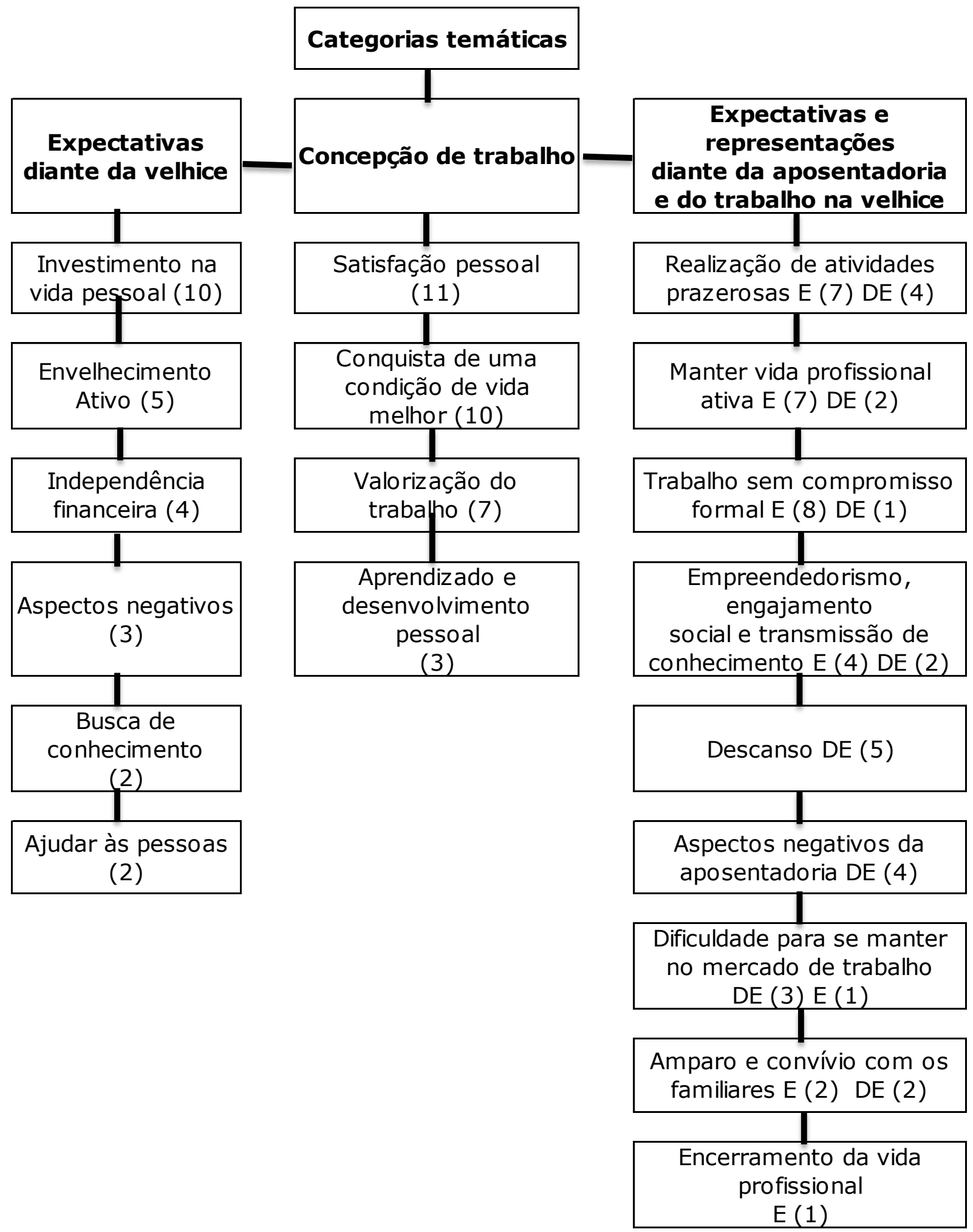

Figura 1: Frequência das categorias e subcategorias temáticas da Análise de Conteúdo. Legenda: E (Entrevistas); DE (Desenho Estória). 


\section{Expectativas diante da velhice}

Com relação ao tema "expectativas diante da velhice", grande parte dos participantes apresentou conteúdos relativos à necessidade de investimento na vida pessoal. Foi significativa para os participantes a relação entre lazer, viagens e equilíbrio para a vida familiar como fatores de qualidade de vida. Buriti (2010) afirma que para a continuidade do desenvolvimento pessoal e superação de dificuldades inerentes à velhice, é necessário estar engajado em atividades de lazer. Os participantes destacaram o desejo de viajar, por exemplo: "Me imagino viajando com a família para as praias do nordeste" (P2) e "Às vezes também passear né, fazer coisas que eu não pude fazer esse tempo todo" (P10).

$\mathrm{Na}$ literatura o lazer turístico é apontado como o mais significativo, pois proporciona novas experiências, sociabilidade e comunicabilidade. Investir no lazer é percebido, pelos participantes, como uma ruptura na rotina e inverso ao trabalho. Eles apresentaram uma visão otimista de uma velhice bem-sucedida que dá sentido à expectativa diante do envelhecer.

A esse respeito, Neri e Vieira (2013), em estudo realizado com 1.451 idosos, concluíram que a manutenção de atividades avançadas de vida diária, de natureza social e de lazer e cultura proporcionam motivação para relações sociais, integração social e produtividade, que são elementos que integram o conceito de velhice bem-sucedida. Apontaram também que essas atividades, facilitam a ligação do idoso com as ações e papéis sociais, permitindo que sejam reconhecidos e valorizados como ativos e produtivos em termos sociais, físicos, intelectuais, organizacionais, de lazer e política.

Alguns participantes consideram a importância de vivenciar a velhice de uma forma ativa. Enfatizaram, assim, que a velhice vivenciada dessa forma está associada à menor probabilidade de aparecimento de doenças nessa etapa da vida, por exemplo: "Vejo a velhice assim, produzindo fisicamente enquanto eu puder, fazendo as minhas corridas" (P9). Em relação a esse aspecto, é importante salientar que o envelhecimento ativo se baseia na condição de uma boa qualidade de vida, através dos pilares facilitadores relacionados à ação de saúde, participação e segurança (Brandão, 2009; Franco \& Barros Jr., 2013). Ferreira et al. (2010) constataram, em pesquisa sobre representações da velhice, que a percepção do idoso é otimista em relação à velhice quando é associada à palavra ativa, sendo que esta representa plenitude e qualidade de vida.

Para alguns participantes ainda, as expectativas diante do envelhecimento estão associadas ao desejo de ter independência financeira e manter o padrão de vida conquistado. Atribuíram à independência financeira a possibilidade de exercerem autonomia, assim segundo o participante (P11): "Tenho que batalhar agora para mais tarde não depender dos outros... Conquistar algum fruto", Bredemeier et al. (2011), observaram em estudo que a autonomia e a 
independência financeira são indicadores abrangentes de qualidade de vida para os idosos. Para Fernandes, Gonçalvez e Oliveira (2012), a condição financeira favorável propicia segurança e independência. Em diversos estudos verificou-se a importância que é dada ao fator financeiro como facilitador para o status de qualidade de vida no envelhecimento.

Os aspectos negativos do envelhecimento foram ressaltados por poucos participantes, sendo que foram apontadas a desvalorização do idoso diante da sociedade e da família, além da possibilidade de abandono e as possíveis complicações com a saúde, por exemplo: "Eu imagino minha velhice ficando esclerosado, dando trabalho para meus filhos ou talvez até indo para um asilo" (P13). De um modo geral, apresentaram uma preocupação com a fragilidade diante da velhice. Em pesquisa realizada verificou-se que as diferentes formas de envelhecer podem estar relacionadas a preocupações causadas por maior vulnerabilidade a doenças, mudanças corporais, perda do status familiar e participação social como um todo (Araújo, Nascimento, \& Amaral, 2011).

A busca de conhecimento e o desejo de ajudar as pessoas na velhice também foram considerados unidades de significado na análise realizada. Assim, alguns participantes relataram: "Pretendo fazer um curso de inglês" (P5) e "... quero intensificar muito no consultório, atendendo, ajudando as pessoas" (P9), mostrando, desse modo, querer continuar o seu desenvolvimento através do aprendizado de uma língua ou estudo de uma área diferente do conhecimento e ajudar as pessoas. Destaca-se o ensino e aprendizagem como a possibilidade do idoso multiplicar suas experiências, ajudando as pessoas de seu convívio de maneira contínua (Baltes, 2000; Neri, 2006).

A subcategoria "ajudar as pessoas na velhice" também está relacionada às expectativas de alguns participantes. Através de suas habilidades profissionais e conhecimentos específicos demonstraram interesse em compartilhar com as demais pessoas. Lempke e Barbosa (2012), em estudo realizado sobre educação e envelhecimento na perspectiva Life-Span, identificaram que as aquisições de novos saberes são fundamentais para a realidade do idoso, sendo o objetivo principal repassar conhecimento aos outros. Erikson (1902-1994), na formulação de sua teoria sobre os estágios de desenvolvimento psicossocial, considerou que na velhice ocorre uma crise psicossocial entre integridade versus desesperança, que deve resultar como força básica dessa fase a sabedoria. Nesse sentido, o idoso, a despeito do declínio físico e mental, mostra um interesse ativo pelo mundo, o que favorece que possa deixar um legado com a conotação de uma "herança", para as futuras gerações. Esse aspecto da teoria está relacionado aos resultados ao longo da vida, pois o sentido que é dado ao ato de ajudar é revelado como uma possibilidade de deixar alguma contribuição significativa para alguém (Hall, Lindzey, \& Campbell, 2000). 


\section{Concepção de trabalho}

No que diz respeito ao tema "concepção de trabalho", a maioria dos participantes trouxe aspectos relacionados à satisfação pessoal. Por exemplo: "Tenho sensação de importância, de gratificação, além da renda financeira" (P4) e "O trabalho é gratificante, não é só fator dinheiro" (P15). Os participantes enfatizaram gostar de suas atividades profissionais, aliado às sensações de orgulho por continuarem trabalhando e sentimento de gratificação. Ressaltaram que o trabalho não significava somente o salário, mas sim o amor pela profissão. Segundo Paschoal e Tamoyo (2008), a satisfação no trabalho está intrinsicamente relacionada aos aspectos cognitivos e afetivos de bem-estar. Em pesquisa realizada com 317 trabalhadores de empresas privadas e públicas verificou-se que a concepção de trabalho foi associada à satisfação e realização pessoal, simbolizadas na construção da felicidade pessoal. Em estudo sobre significados atribuídos ao trabalho com 1.448 jovens, Fernandes et al. (2012) constataram que o trabalho representou mais do que uma questão financeira, mas uma fonte da satisfação pessoal.

A conquista de uma condição de vida melhor está também associada à concepção de trabalho para grande parte dos integrantes. De acordo com os participantes: "De conquista... significa que é uma renda que me ajuda, é um salário a mais" (P7) e "Meu trabalho... Eu dependo dele... é meu meio de sobrevivência" (P14). Tanto os pesquisados aposentados quanto os que ainda não são, relataram que o trabalho possibilita cuidar dos familiares com segurança, conquistar um padrão de vida melhor e fonte de renda para sobrevivência. A atividade remunerada colabora para uma melhor qualidade de vida pessoal e familiar. Além de satisfação, o trabalho pode ser visto também como fonte de salário e estabilidade financeira, dessa forma, significa sobrevivência e garantia de suprir necessidades básicas (Sobral, Gonçalves, \& Coimbra, 2009). Zanelli, Silva e Soares (2010), em pesquisas com grupos de funcionários de pré-aposentadoria, levantaram que o labor representa estabilidade e segurança através de um bom salário, sendo destacada como uma função econômica provedora de necessidades.

Cerca de metade dos entrevistados da pesquisa apresentou a valorização do trabalho como elemento essencial em suas vidas associado ao sentimento de sentirem-se valorizados. Principalmente quando se está envelhecendo, o trabalho é extremamente importante para a pessoa sentir que não perdeu o direito de viver com dignidade, como se pôde observar na fala do participante (P10): "É tudo para mim, é à base de tudo para mim esse trabalho... sem ele eu não sou nada". A esse respeito, alguns autores, como Soares e Costa (2011), Zanelli et al. (2010) e Glanzner, Olschowsky e Kantorski (2011), discutem que o trabalho é central para as pessoas, sendo um elemento imprescindível para a construção da identidade, além de uma fonte de autoestima. A partir de sua identidade profissional, o trabalhador busca atividades dotadas de sentido e significado 
consistente de valores que é peculiar a ele. A valorização que é dada a pessoa é um forte componente para a autoestima e orgulho de si no ambiente laborativo.

O trabalho foi relacionado ao aprendizado e possibilidade de desenvolvimento pessoal para alguns participantes, por exemplo: "É sempre um aprendizado para mim, para ensiná-los a trabalhar da forma que eu sei e dá resultados" (P4). Os conteúdos trazidos foram a troca de aprendizados que é proporcionada ao liderar equipes, a possibilidade de desenvolvimento pessoal e a atualização de novos saberes através da prática profissional em uma organização fonte de realizações pessoais. Zanelli e Silva (2008) assinalam que o desenvolvimento pessoal é possível através das transformações da percepção de si e do ambiente de trabalho. Nesse contexto, o desenvolvimento de atributos pessoais, exploração do próprio potencial e aprendizados são importantes para a percepção de trabalho. Lemos e Passos (2012), em estudo com docentes em enfermagem sobre satisfação e frustração no desempenho do trabalho, revelaram que a convivência do idoso com as demais pessoas na organização gera aprendizagem significativa em ambos os lados. Ainda apontaram que os profissionais buscam situações que possam construir e experimentar novos aprendizados e assim contribuir para o desenvolvimento pessoal no labor.

Expectativas e representações diante da aposentadoria e do trabalho na velhice

Para uma melhor compreensão da última temática, "expectativas e representações diante da aposentadoria e do trabalho na velhice", foram considerados os conteúdos trazidos pelos participantes relativos à aposentadoria e trabalho na velhice. Optou-se por incluir nesse tema as estórias relativas aos desenhos gerados na realização do Procedimento Desenhos-Estórias com Tema, tanto no que diz respeito aos desenhos realizados com a temática do idoso que trabalha quanto ao idoso aposentado. Verificou-se que, embora alguns participantes já estejam aposentados, esses continuam trabalhando, portanto, a representação da aposentadoria tem um significado semelhante à continuidade do trabalho. Desse modo, para os cinco participantes do estudo que continuam exercendo suas atividades profissionais, a aposentadoria não foi percebida como encerramento do trabalho.

A maioria dos participantes atribuiu às representações e expectativas diante da aposentadoria e do trabalho na velhice a possibilidade da realização de atividades prazerosas. Esse conteúdo foi observado tanto nas entrevistas quanto nas histórias relativas aos desenhos, como, por exemplo: "Jogar uma bolinha com churrasquinho, viajar e curtir a família" (P2) e "Viajar de moto... curtir a vida, conhecer o Brasil" (P13). Em vista disso relacionaram atividades prazerosas aos momentos de lazer pessoal e em família, citaram os exemplos de iniciar ou continuar hobbies e destacaram os passeios e viagens como forte desejo.

Buriti e Ferrari (2011), em estudos sobre lazer na velhice, verificaram que a atividade de lazer no período do envelhecimento para a pessoa aposentada 
tem o objetivo de reparar desgastes físicos e mentais decorrentes do longo período de trabalho, além de preencher o tempo livre e assim evitar o tédio. Outro fator importante é a continuação do desenvolvimento pessoal ligado à fonte de prazer. Corroborando os resultados desse estudo, Bitencourt, Gallon, Batista e Piccinini (2011), em pesquisa realizada sobre o sentido do trabalho no processo de aposentadoria, identificaram que, para a maioria das pessoas, as expectativas em relação à aposentadoria referem-se a viagens e momentos de lazer em família. Ressaltaram que esse fato pode estar relacionado à necessidade de se ter outra ocupação ou algo que possa preencher a lacuna e o tempo que o emprego deixou.

Manter a vida profissional ativa está relacionado às expectativas também de parte significativa dos participantes. Assim, alguns homens relacionaram o fato de manter a vida profissional ativa ao aspecto financeiro destinado a manter o padrão de vida. Outros afirmaram que o encerramento se dará somente por questões de doenças, assim: "Continuará trabalhando enquanto tiver saúde" (P12) e "Eu vou tentar alguma coisa de motorista... O que não quero é ficar parado, entendeu?" (P13). De acordo com os autores Wajnman et al. (2004), a maior participação de idosos acima de 60 anos na força de trabalho é uma consequência do aceleramento populacional. A condição desfavorável da previdência social impacta no rendimento salarial do idoso. Manter um padrão de vida tem o caráter fundamental para a manutenção de sua renda pessoal e familiar. Nesse sentido, Sá et al. (2011) acrescentam que o indivíduo que trabalha tem outra razão que diz respeito à necessidade de se manter produtivo e valorizado. Em estudos sobre o papel do novo idoso, foi constatado que, de forma geral, a aposentadoria é encarada pelas pessoas como um benefício possível, porém não vinculada ao encerramento do labor, pois grande parte das pessoas aposentadas considera-se produtiva trabalhando e demonstra grande preocupação em manter-se ativa (Moreira, 2011; Ribeiro 2012; Scortegagna \& Oliveira, 2012).

Notou-se que uma parte significativa dos participantes manifestou a vontade de, na etapa da velhice, realizar trabalhos informais em um ambiente mais flexível, relacionados tanto ao prazer quanto a complementação de renda e a necessidade de continuarem ativos, exemplos: "Quero fazer algo informal, que me agrade muito. Não importa se terá dinheiro... Através da arte criar uma renda extra" (P4) e "Fazer serviços leves, algumas coisinhas para não ficar parado, só isso" (P10). Soares e Costa (2011) destacam a questão de novos projetos de trabalho na velhice relacionados à busca por adaptação e superação das dificuldades financeiras típicas dessa fase. É uma forma de romper certos paradigmas e buscar segurança em trabalhos de grande afinidade, além de ser uma expressão positiva quanto ao trabalho na velhice e aposentadoria e, quem sabe, a retomada de desejos do passado a fim de concretizá-los. 
As expectativas quanto ao trabalho ou aposentadoria estão ligadas, para alguns participantes, à possibilidade de, nessa fase da vida, empreender, ter engajamento social e poder transmitir seus conhecimentos. Assim, expressaram a vontade de continuarem ativos através da criação de um negócio, repassar suas experiências aos mais jovens e atuar em projetos sociais, por exemplo: "Desfrutar dos bens que eu vou criar... Negócio próprio que quero abrir" (P11). Segundo Soares e Costa (2011), o idoso só consegue realizar-se como "produtor", sendo uma forma de evitar a descontinuidade da identidade profissional e associar o envelhecimento a algo positivo. Peres (2014), em pesquisa realizada com idosos empreendedores, verificou que 0 empreendedorismo é uma alternativa de investimento social e econômico na velhice. Constatou que empreender na maturidade envolve valorizar escolhas e ganhos adquiridos, e as possíveis perdas relacionadas à velhice, além de contribuir para uma melhor qualidade de vida e possibilidades de novas experiências e aprendizados.

Em estudos com pessoas na pré-aposentadoria, os autores Soares e Costa (2011) e Zanelli et al. (2010) observaram que o voluntariado em Organização não governamental (ONG) é um desafio para quem se aposenta. Tem a conotação de aceitar e descobrir outras fontes de realização e valorização. Foi observado que os idosos que passaram grande parte da sua vida trabalhando acentuam a vontade de repassar todo o seu conhecimento aos mais jovens nessa fase.

Alguns participantes demonstraram associar o trabalho ou aposentadoria na velhice à possibilidade de aproveitar a vida apenas descansando. É importante notar que esse conteúdo apareceu de modo significativo nas unidades de Desenhos-Estórias com Tema, por exemplo: "Estaria aproveitando um pouco a vida da maneira a descansar" (P4). Zanelli et al. (2010) verificam que uma das possibilidades da aposentadoria é o descanso remunerado, que proporciona mais tempo para a realização de outras atividades. Andrade e Rafalski (2013) constataram em pesquisa sobre representações de aposentadoria entre homens e mulheres de meia-idade que o descanso na aposentadoria é associado à possibilidade de focar nos aspectos familiares e lazer. Santo, Góes e Chibante (2014) verificaram os limites e possibilidades do idoso frente à aposentadoria e notaram que o descanso é ligado a uma melhor qualidade de vida nessa fase para o aposentado. De forma geral, os estudos em relação à aposentadoria, não mostram o "descanso" como a única forma de aproveitar a velhice.

Os aspectos negativos da aposentadoria foram observados somente nos desenhos por quatro participantes. Estes trouxeram conteúdos relacionados ao desrespeito de seus direitos perante a sociedade, problemas de saúde, depressão e morte, ambos causados pelo encerramento das atividades profissionais, exemplo: "Poderá entrar em depressão ou ter alguma doença grave por falta de exercícios" (P14). Zanelli et al. (2010) apontam que nessa fase a pessoa pode 
ter uma visão positiva e, ao mesmo tempo, menos otimista da velhice. Trata-se de uma ambiguidade própria da aposentadoria, que oscila de acordo com a história de vida e contexto social. Os fatores negativos são decorrentes, da redução da capacidade financeira, perda de vínculos afetivos do ambiente de trabalho, perda de status profissional e sentimentos de inutilidade e insegurança. Em outras palavras, a identidade que foi construída através do trabalho é desconstruída.

Com relação à dificuldade em manter-se no mercado de trabalho, também quatro participantes destacaram a desvalorização do idoso, a dificuldade de recolocação profissional e a concorrência injusta com os jovens pela defasagem tecnológica e educacional, assim, para o participante (P6): "Vai ser muito difícil concorrer com pessoas jovens... questão de ensino e estudo, eu não sou graduado". Goulart Jr. et al. (2009) afirmam que as empresas não aproveitam os recursos de trabalho das pessoas mais velhas. Isso se estabelece, pois há uma preferência pelos mais jovens, vistos com maior agilidade para produção, flexíveis a mudanças de rotinas e com habilidades tecnológicas. Desse modo, o idoso que pretende continuar trabalhando após a aposentadoria deve adequar-se às novas tendências e possibilidades de trabalho de acordo com as suas habilidades. Ainda com relação à dificuldade de recolocação profissional na velhice, Trento (2008) identificou, em estudo realizado sobre os idosos aposentados que continuam suas atividades profissionais, que a escolaridade tem ficado a desejar. Destacou que se deve ter um olhar diferenciado dirigido a esses profissionais, a fim de assegurar respeito às qualidades e às limitações deste indivíduo.

O aspecto relativo às questões ligadas à família, como o auxílio nas questões financeiras e o desejo de cuidar dos filhos e netos, teve destaque para alguns participantes, por exemplo: "Capinando o quintal... para o sustento da minha família... faz o que tiver para ajudar a família" (P7). De acordo com Witter e Camilo (2011), a família constitui uma dinâmica essencial na vida das pessoas e representa uma unidade que engloba relações afetivas, sociais, financeiras e culturais. Muitos idosos tornaram-se de fundamental importância no núcleo familiar, na maioria das vezes é o provedor financeiro do lar, cuidador dos netos e até mesmo apoio psicológico aos filhos. Na velhice a pessoa tem um papel na sociedade que é reflexo do aumento da expectativa de vida, o que envolve ainda uma intergeracionalidade.

Quanto ao encerramento da vida profissional, somente um participante apontou o desejo de encerrar as atividades de trabalho, no entanto, em sua concepção, isso ocorreria somente aos 80 anos, exemplo: "Quando estiver bem velhinho mesmo, com 80 anos não pretendo trabalhar" (P2). Os autores Neri (2014) e Zanelli et al. (2010) consideram o encerramento da carreira profissional como uma transição que necessita de reflexão e preparação. O desligamento 
deve ser aos poucos, pois impacta diretamente na vida social e pessoal. Implica mudança de papéis e status que condicionam a uma revisão da existência.

\section{Análise qualitativa do conjunto da produção Desenhos-Estórias com Tema}

Para essa análise qualitativa foi considerada a unidade do conjunto Desenhos-Estórias com Tema, produzidas pelos participantes quanto à representação de uma pessoa idosa que trabalha e a representação de um aposentado. Foram destacados alguns significados em relação à expectativa de trabalho na velhice e na aposentadoria.

Com relação aos temas mais frequentes no desenho do idoso que trabalha, os participantes apresentaram conteúdos relacionados ao empreendedorismo e à transmissão de conhecimento. Conforme discutido anteriormente, empreender e transmitir experiências envolve o sentimento de sentir-se útil, pois permite a capacidade de novas conquistas e garantia de uma velhice ativa (Neri, 2014; Peres, 2014). A oportunidade de aprendizagem e transmissão de conhecimento são fatores que proporcionam maior autonomia e segurança aos idosos. Para a Organização Pan-Americana da Saúde (2005, como citado em Organização Mundial de Saúde - OMS) e Serapião, Puterman, Ianae e Carvalho (2013), o bem-estar físico, psíquico e social possibilita um envelhecimento ativo. Para muitos idosos, a oportunidade de trabalhar após a aposentadoria, seja empreendendo ou trabalhando de maneira informal, é gratificante e favorece uma maior qualidade de vida.

Soares e Sarriera (2013), em estudo com grupos de orientação para a aposentadoria, identificaram que a temática da nova geração de aposentados tem relação a estarem sempre em ação, fazendo algo e preenchendo o tempo. Ainda se destaca que apareceram nesses desenhos conteúdos relacionados ao trabalho como parte da identidade social e possibilidade financeira. Nesse sentido, Felix (2012) afirma que a maioria dos idosos ocupa a posição de chefes de família e esse novo envelhecer não deve ser confundido com o não envelhecer, em que o idoso tem uma vida de trabalho sem fim. Estes temas foram presentes nas entrevistas e nas representações gráficas.

A representação de conteúdos de depressão, morte e problemas de saúde causados pelo encerramento do trabalho, relacionados ao aspecto negativo do trabalho na velhice, foi observada em quatro desenhos. Zanelli et al. (2010) e Soares e Costa (2011) constataram que as pessoas que estão próximas de encerrarem as atividades profissionais carregam certa ansiedade ao ter que pensar na dependência de cuidados de saúde e também preocupações com o desrespeito da sociedade quanto aos direitos do idoso. É notado o sentimento de fragilidade e impotência frente ao fim da vida e às incertezas. Com relação ao conteúdo das entrevistas, não foram observados aspectos negativos, esses apareceram somente nos desenhos. 
No segundo desenho referente à pessoa aposentada houve destaque para a idealização da maioria dos participantes quanto ao descanso como prioridade após o término do vínculo de trabalho pela aposentadoria. Nesse sentido o descanso surgiu relacionado à possibilidade de "não fazer nada", exemplo: "Vou descansar... Quero descansar" (P8). Nesse sentido há uma diferença do conteúdo expresso nas entrevistas, em que o descanso apareceu como a possibilidade de lazer. Soares e Costa (2011) e Zanelli (2012), em estudos sobre trajetórias de vida e projetos na aposentadoria, verificaram que o descanso foi relacionado ao tema lazer como um planejamento para a realização de viagens, atividades artísticas, promoção de encontros sociais, práticas de esportes e hobbies.

É importante observar que, com relação ao descanso, os participantes conseguiram conceber esta possibilidade somente através da representação dos desenhos, pois no discurso essa condição é vislumbrada como algo não permanente e sim como algo possível apenas através de certas atividades prazerosas. Presume-se que o descanso em seu total significado apareceu exclusivamente nos desenhos, visto que é um desejo latente e pouco aceito socialmente, justamente por estar contrário aos ideais do envelhecimento ativo relacionado à produtividade e qualidade de vida.

Segundo Aiello-Vaisberg (2013), é possível compreender que os significados elaborados somente nos desenhos representam os aspectos emocionais e intersubjetivos, além da comunicação emocional ser facilitada nesse teste. Partindo do pressuposto de que a vontade em descansar fica somente no desejo apenas dos participantes, sugere-se que é devido a um contexto desfavorável de políticas públicas e previdência social que obriga o trabalhador mais velho a continuar suas atividades remuneradas, e com isso não permite que o idoso se dedique somente aos seus interesses $e$, inclusive, ao descanso remunerado.

Ainda nessa mesma unidade gráfica os participantes citaram a possibilidade de trabalharem de forma leve para complementar a renda e ter o sentimento de utilidade, o que também foi observado no conteúdo das entrevistas de alguns dos participantes. Conforme discutido anteriormente em estudo sobre aposentadoria, Cintra, Ribeiro e Andrade (2010) constataram que os aposentados continuam trabalhando de maneira informal para ajudar na renda, ampliar os vínculos e vivenciar o trabalho de maneira mais leve. De maneira geral, verificou-se que as entrevistas e os desenhos se complementaram e conseguiram mostrar, no geral, o panorama das representações sociais dos homens de meia-idade em relação ao trabalho na velhice. 


\section{CONSIDERAÇÕES FINAIS}

O presente procurou, de um modo geral, identificar as percepções de trabalho na velhice e aposentadoria para homens na meia idade. Para tanto, foram entrevistados 15 homens na faixa etária entre 50 e 59 anos, em sua grande maioria casados, com filhos e exercendo atividades profissionais com vínculo formal. Identificou-se que as expectativas diante da aposentadoria estão associadas ao desejo em praticar atividades prazerosas e constatou-se, ainda, que as expectativas e concepções de trabalho na velhice estão relacionadas tanto à continuidade, quanto a sua ressignificação nessa fase da vida.

Constata-se um novo cenário de longevidade em que os idosos estão vivendo mais e com a responsabilidade de continuar cuidando da família. Diante disso, os participantes na meia-idade não têm em seus planos profissionais o encerramento do trabalho, mas sim uma ressignificação desse. O que leva a observar que o trabalho, não importa em que idade, se pensado positivamente é um fator que agrega no processo de envelhecimento. Em relação a isso, constatou-se um conjunto de fatores associados a essa visão positiva dos participantes como as práticas de lazer, o reconhecimento e valorização da sociedade, a oportunidade de aprender, ajudar as pessoas e independência financeira. Os aspectos negativos do envelhecimento são observados na desvalorização e abandono daquele que não produz mais fisicamente. Ao considerar o idoso como produtivo, as pessoas na meia-idade almejam novos ou antigos projetos para vivenciar na velhice.

Verificou-se, em relação ao trabalho na velhice, que o desejo de se dedicar somente ao lazer e família, entre outros aspectos, é algo muito presente, porém os dados da realidade sobre a instabilidade da previdência social e a necessidade de garantia do padrão de vida conquistada, podendo, assim, proporcionar estabilidade financeira aos familiares faz com que a expectativa dos participantes seja, de modo geral, de continuar suas atividades remuneradas.

Com relação à aposentadoria, a continuidade do trabalho para os participantes está relacionada à possibilidade de realizar atividades prazerosas e ter mais tempo para si mesmo, prolongando assim sua vida ativa. Nesse contexto, é importante observar também que o prolongamento do trabalho na velhice está associado, para os participantes, não só a uma necessidade relacionada ao aspecto financeiro, mas sim é expressa como algo que pode ser ressignificado, adquirindo assim novas dimensões representadas, por exemplo, no trabalho sem compromisso formal, empreendedorismo ou engajamento social.

A realização da técnica projetiva favoreceu a expressão de conteúdos latentes relacionados à expectativa do descanso na velhice, bem como de aspectos negativos ligados ao trabalho na velhice, que não foram expressos nas entrevistas. Os resultados corroboram aos dados encontrados na literatura sobre 
o tema. Ressalta-se que é necessário realizar novas pesquisas mais amplas com pessoas na meia-idade e que possam contemplar, além de um maior número de participantes, também a participação de mulheres na meia-idade.

\section{REFERÊNCIAS}

Abras, R., \& Sanches, R. N. (2010). O idoso e a família. In J. Mello Filho, \& M. Burd (Org). Doença e família (pp. 233-241). São Paulo, SP: Casa do Psicólogo.

Aiello-Vaisberg, T. M. J. (1997). Desenhos-Estórias com Tema. In W. Trinca (Org.), Formas de Investigação clínica em psicologia: O procedimento de desenhos-estórias e desenhos de famílias com estórias. São Paulo, SP: Vetor.

Aiello-Vaisberg, T. M. J., \& Ambrósio, F. F. (2013). Rabiscando DesenhosEstórias com Tema: Pesquisa psicanalítica de imaginários coletivos. In W. Trinca (Org.), Procedimentos de Desenhos-Estórias: Formas derivadas, desenvolvimento e expansões. São Paulo, SP: Vetor.

Albornoz, S. (2000). O que é trabalho (6a ed.). São Paulo, SP: Brasiliense.

Andrade, A. L., \& Rafalski, J. C. (2013). Diferenças e semelhanças nas representações de aposentadoria entre homens e mulheres de meia-idade. In Anais do Colóquio de Orientação Profissional de Carreira e para a Aposentadoria. Florianópolis, SC.

Araújo, L., Nascimento, E. C., \& Amaral, E. B. (2011). Corpo e velhice: um estudo das representações sociais entre homens idosos. Psicologia Ciência e Profissão, 31(3) 468-481. doi:10.1590/S1414-98932011000300004.

Antunes, P. C., \& Silva, A. M. (2014). A produção científica brasileira e a problematização acerca da meia-idade: um estudo a partir de periódicos do campo da educação física. Revista Estudos Interdisciplinares em Envelhecimento, 19(1), 9-26.

Baltes, P. B. (2000). Autobiographical reflections: From developmental methodology and lifespan psychology to gerontology. In J. E. Birren, \& J. F. Schroots (Eds.), A history of geropsychology. In autobiography (pp. 1-6). Washington, DC: American Psychological Association.

Bardin, L. (2006). Análise de conteúdo. Lisboa, Portugal: Edições 70.

Bitencourt, M. B., Gallon, S., Batista, K. M., \& Piccinini, C. V. (2011). Para além do tempo de emprego: o sentido do trabalho no processo de aposentadoria. Revista de Ciências de Administração, 13(31), 30-57. doi:10.5007/21758077.2011v13n31p30.

Brandão, S. J. (2009). Lazer para o idoso ativo como fator de qualidade de vida no processo de envelhecimento. (Tese de Doutorado). Universidade Católica do Rio do Grande do Sul, Porto Alegre, SC., Brasil. 
Bredemeier, L. M. C., Wolff, H. S, Santos, M. R. M., Accurso, A., Soares, P. A., Riegel, C., \& Noguez, C. S. (2011). Autonomia na velhice: Concepções de idosos participantes de um programa de ação social. Revista Estudos Interdisciplinares em Envelhecimento, 16[Edição especial], 371-384.

Buriti, M. A., \& Ferrari, M. S. L. (2011). Recreação e lazer como forma de interação social do idoso. In C. Witter, \& M. A. Buriti. Envelhecimento e contingências da vida. Campinas, SP: Alínea.

Buriti, M. A. (2010). Lazer e envelhecimento. In P. G. Witter, (Org.), Envelhecimento: Referenciais teóricos e pesquisas (2a ed.). Campinas, SP: Alínea.

Cintra, T. S., Ribeiro, D. F., \& Andrade, A. S. (2010). O cotidiano de aposentados que continuam trabalhando de maneira informal na indústria calçadista: Percepções sobre a aposentadoria e o trabalho atual. Revista Cadernos de Psicologia Social do Trabalho, 13(2). doi: http://dx.doi.org/10.11606/issn.1981-0490.v13i2p277-287.

Erikson, E. H. (1998). O ciclo de vida completa. Porto Alegre, RS: Artmed.

Felix, J. (2012). Desafios da previdência social para um país que envelhece e o risco da aposentadoria como prêmio. In V. M. Berzins, \& C. M. Borges. Políticas Públicas para um país que envelhece. São Paulo, SP: Martinari.

Fernandes, S. F. Gonçalves, C. M., \& Oliveira, J. P. (2012). Adaptação e validação da Escala de Significados Atribuídos ao Trabalho ESAT. Revista Brasileira de Orientação Profissional, 13(2), 183-195.

Ferreira, O. G. L., Maciel, S. C., Silva, A. O., Santos, W. S., \& Moreira, M. A. S. P. (2010). O envelhecimento ativo sob o olhar de idosos funcionalmente independentes. Revista da Escola de Enfermagem da USP, 44(4), 10651069. doi:10.1590/S0080-62342010000400030.

Franco, C. M. B., \& Barros Jr., F. O. (2013). O envelhecimento ativo e o espaço acadêmico: Significações das pessoas idosas do programa integração de gerações em Teresina-PI. Revista Faculdade Santo Agostinho, 10(4), 334346.

Fontes, A. P. (2010). Resiliência, segundo o paradigma do desenvolvimento ao longo da vida (life-span). Revista Kairós Caderno Temático, 7, 8-20.

Goulart Jr., E. D., Mergulhão, L. R, Canêo, L. C, Najm, M. B., \& Lunardelli, M. C. F. (2009). Considerações sobre a terceira idade e o mercado de trabalho: questionamentos e posibilidades. Revista Brasileira de Ciências do Envelhecimento Humano. 6 (3), 429-437.

Glanzner, H. C., Olschowsky, A., \& Kantorski, P. L. (2011). O trabalho como fonte de prazer: Avaliação da equipe de um Centro de Atenção Psicossocial. Revista Escola Enfermagem USP, 45(3), 716-21, doi:10.1590/S008062342011000300024.

Hall, S. C., Lindzey, G., \& Campbell, B. J. (2000). Erikson pós-teoria Freudiana. In Teorias da Personalidade (4a ed.). Porto Alegre, RS: Artmed. 
Instituto Brasileiro de Geografia e Estatística (2013). Síntese de Indicadores Sociais: uma análise das condições de vida da população Brasileira. Recuperado dehttp://biblioteca.ibge.gov.br/visualizacao/livros/liv66777.pdf.

Instituto Nacional Seguro Social (2014). Informes de Previdência Social. Recuperado de http://www.previdencia.gov.br/publicacoes/informes-deprevidencia-social/.

Instituto de Pesquisa Econômica Aplicada (2009). Envelhecimento Populacional Recuperado

http://www.ipea.gov.br/portal/index.php?option=com_content.

Jung, C. G. (1971). As etapas da vida humana. In $A$ natureza da psique. São Paulo, SP: Vozes.

Lemos, M. C. \& Passos, P. J. (2012). Satisfação e frustração no desempenho do trabalho docente em enfermagem. Revista Mineira de Enfermagem, 16(1), 48-55. doi:1415-27622012000100007.

Lempke, S. N. N., \& Barbosa, A. J. G. (2012). Educação e envelhecimento: Contribuições da perspectiva Life-Span. Revista Estudos de Psicologia, 29(1), 647-655, doi: 10.1590/S0103-166X2012000500001.

Minayo, M. C. (2006). Visão antropológica do envelhecimento humano. In Velhices: Reflexões contemporâneas. São Paulo, SP: Sesc.

Moreira, J. O. (2011). Imaginários sobre aposentadoria, trabalho, velhice: Estudo de caso com professores universitários. Revista Psicologia em Estudo, 16(4), 541-550.doi: 10.1590/S1413-73722011000400005.

Moreira, J. O. (2012). Mudanças na percepção sobre o processo de envelhecimento: reflexões Preliminares. Revista Psicologia: Teoria e Pesquisa, 28(4), 451-456.doi: 10.1590/S0102-37722012000400003.

Neri, A. L. (2006). O legado de Paul B. Baltes à Psicologia do Desenvolvimento e do Envelhecimento. Revista Temas em Psicologia, 14(1), 17-34.

Neri, A. L., \& Vieira, M. A. L. (2013). Envolvimento social e suporte social percebido na velhice. Revista Brasileira de Geriatria e Gerontologia, 16(3), 419-432. doi:10.1590/S1809-98232013000300002.

Neri, A. L. (2014). Palavras-chave em Gerontologia (4a ed.). Campinas, SP: Alínea.

Organização Mundial da Saúde. (2005). Envelhecimento ativo: uma política de saúde. Brasília, DF: Organização Pan-Americana da Saúde. Recuperado de http://bvsms.saude.gov.br/bvs/publicacoes/envelhecimento_ativo.pdf.

Paschoal, T., \& Tamoyo, A. (2008). Construção e validação da escala de bemestar no trabalho. Revista Avaliação Psicológica, 7(1), 11-22.

Peres, A. (2014). Empreendedorismo e envelhecimento: Perspectivas de uma nova relação de trabalho na maturidade. (Dissertação de Mestrado), Universidade São Judas Tadeu, São Paulo, SP, Brasil. 
Ribeiro, S. B. (2012). A força de trabalho da Fiocruz e o processo de aposentadoria. (Dissertação de Mestrado). Escola Nacional de Saúde Pública, Rio de Janeiro, RJ, Brasil. Recuperado de bvssp.icict.fiocruz.br/lildbi/docsonline/get.php?id=2903.

Sá, M. A. A. S, \& Souza, D.M.R. (2015). Envelhecimento ou desenvolvimento profissional? Revista Trabalho e Educação, 24(2), 267-280.

Sá, S. M. C, Souza, O. D. V. M, Caldas, P. C, Lisboa, L. T. M., \& Tavares, A. F. K. (2011). O idoso no mundo do trabalho: configurações atuais. Revista Cogitare Enfermagem, 16(3), 536-542.

Santo, F. H. E., Góes, P. M. F., \& Chibante, C. L. P. (2014). Limites e possibilidades do idoso frente à aposentadoria. Revista Kairós Gerontologia, 17(4), 323-335.

Scortegagna, A. P., \& Oliveira, S. C. R. (2012). Idoso: um novo ator social. In Anais do Seminário em Pesquisa em Educação da Região Sul. Florianópolis, SC.

Serapião, S. C., Puterman, P., Ianae, D., \& Carvalho, G. (2013). Iniciativas voltadas para a maior idade empreendida pela Via Gutemberg. In T. E C., Rosa, A. E. S. Barroso, \& M. C. P. Louvison, Velhices: Experiências e desafios nas políticas do envelhecimento ativo. São Paulo, SP: Instituto de Saúde.

Silva, B.R., \& Finocchio, A. L. (2011). A Velhice como marca da Atualidade: uma Visão Psicanalítica. Revista vínculo, 8(2).

Silva, L. P., \& Silva, C. (2014). Idade do Lobo. Revista Portal de Divulgação, 40(4), 49-58.

Soares, P. H. D., \& Costa, B. A. (2011). Aposentação: Aposentadoria para ação. São Paulo, SP: Vetor.

Soares, P. H. D., \& Sarriera, C. J. (2013). O tempo livre na aposentadoria: uma experiência no aposenta-ação. In S. S. Santos, \& A. S. Carlos. Envelhecendo com apetite pela vida. Petrópolis, RJ: Vozes.

Sobral, J. M., Gonçalves, C. M., \& Coimbra, J. L. (2009). O impacto da situação profissional parental no desenvolvimento vocacional dos adolescentes. Revista Brasileira Orientação Profissional, 10(1), 11-22.

Trento G. (2008). Idosos e mercado de trabalho: um estudo sobre os idosos aposentados que continuam trabalhando formalmente no comércio do centro de Florianópolis. (Trabalho de Conclusão de Curso). Universidade Federal de Santa Catarina, Florianópolis, SC, Brasil. Recuperado de http://tcc.bu.ufsc.br/Ssocial285320.pdf.

Trinca, W. (1972). O Desenho livre como Estímulo de Apercepção Temática. (Tese de Doutorado). Universidade de São Paulo, São Paulo, SP, Brasil.

Trinca, W. (2013). Procedimento de Desenhos-Estórias: Formas derivadas, desenvolvimentos e expansões. São Paulo, SP: Vetor. 
Trindade, E. (2002). Hermenêutica do existir do homem de meia-idade: Paternidade, sexualidade e projetos de vida - um olhar à luz de Heidegger (Tese de Doutorado). Universidade de São Paulo, Ribeirão Preto, SP, Brasil.

Turato, R. E. (2005). Métodos qualitativos e quantitativos na área da saúde: Definições, diferenças e seus objetivos de pesquisa. Revista de Saúde Pública, 39(3), 507-514. doi:10.1590/S0034-89102005000300025.

Wajnman, S., Oliveira, A., M. H., C., \& Oliveira, E., L. (2004). Os idosos no mercado de trabalho: Tendências e consequências. In A. M. Camarano. Os novos brasileiros muito além dos 60? Rio de Janeiro, RJ: Ipea. Recuperado de

http://www.en.ipea.gov.br/agencia/images/stories/PDFs/livros/Arq_23_Cap _14.pdf.

Witter, C., \& Camilo, A. B. R. (2011). Família e envelhecimento. In C. Witter, \& M. A. Buriti (Orgs.), Envelhecimento e contingências de vida. Campinas, SP: Alínea.

Zanelli, J. C., \& Silva, N. (2008). Interação humana e gestão: a construção psicossocial das organizações de trabalho. São Paulo, SP: Casa do Psicólogo.

Zanelli, J. C., Silva, N., \& Soares, P. H. D. (2010). Orientação para aposentadoria nas organizações de trabalho: Construção de projetos para o pós-carreira. Porto Alegre, RS: Artmed.

Zanelli, J. C. (2012). Processos Psicossociais, bem-estar e estresse na aposentadoria. Revista Psicologia: Organizações e Trabalho, 12(3), 329340.

Sobre as autoras

Milena Cristina de Freitas é psicóloga pela Universidade São Judas Tadeu e mestranda em Ciências do Envelhecimento pela Universidade São Judas Tadeu. Trabalha nas linhas de psicologia clínica e do envelhecimento e recebe bolsa integral CAPES. Contato: milena.querubim@hotmail.com.

Tatiane Dornelas Campos é psicóloga pela Universidade São Judas Tadeu. Trabalha nas linhas de psicologia clínica e das organizações. Contato: psicologia.dcampos@gmail.com.

Cláudia Aranha Gil é psicóloga clínica e doutora em Psicologia Clínica pela Universidade de São Paulo. Professora no programa de mestrado strictu sensu em Ciências do Envelhecimento. Contato: claudiaagil@uol.com.br.

Recebido em: 16/05/2016 $1^{a}$ revisão em: 09/08/2016 $2^{a}$ revisão em: $12 / 12 / 2016$

Aceito em: $12 / 02 / 2017$ 